REVISTA DE DERECHO UNED, NÚM. 10, 2012

\title{
LAS INVITACIONES A NEGOCIAR
}

\author{
Héctor Daniel Marín Narros \\ Abogado colegiado en Nueva York \\ LLM por la University of California, Berkeley \\ Doctor en Derecho
}

Resumen: Las invitaciones a negociar son figuras precontractuales de frecuente uso en el tráfico jurídico. Se utilizan con la finalidad de iniciar los tratos preliminares. Son documentos unilaterales que contemplan manifestaciones de deseo de iniciar las negociaciones. Por ello no contienen una verdadera voluntad de vincularse ni contemplan los elementos esenciales del contrato que podría suscribirse al finalizar los tratos preliminares. En consecuencia, no pueden ser consideradas ofertas, ni tampoco contratos.

En consonancia con la configuración expuesta, esta institución precontractual constituye un documento que expresa la intención de negociar. En el caso de que sea aceptado supone el inicio de los tratos preliminares. Con ello pueden derivar determinadas obligaciones, como la de negociar de buena fe o la de confidencialidad. Asimismo, puede producir responsabilidad precontractual, cuando haya una legítima confianza en la suscripción de un contrato futuro, se rompan las negociaciones por una causa injustificada y se produzca un daño por tal ruptura. Aunque en el caso de esta figura precontractual, difícilmente concurrirán los mencionados elementos.

Abstract: Request for information are precontractual agreements that are used frequently. The purpose of these agreements is to start the bargain of a prospective contract. They are unilateral documents which contemplate the intent to start the negotiations. For that reason, they do not contain a real intent to be bound. They also do not 
have the essential elements of the prospective contract. Consequently, they cannot be considered as offers or contracts.

As a consequence of the described concept, this precontractual agreement is a document that expresses the intent to negotiate. In the event that it is accepted, the bargain commences. At this point, some obligations may arise, such as the duty to negotiate in good faith or confidentiality. Furthermore, precontractual liability may arise out of it too, when there is a legitimate expectation that the prospective contract will be executed and a real damage has been provoked due to the unjustified break of the negotiations. But those elements will rarely concur when a request for information is used.

Palabras clave: invitaciones a negociar/acuerdos precontractuales.

Key words: request for information/precontractual agreements.

Sumario: I. Introducción. II. Concepto de invitaciones a negociar. II.1. Regulación normativa. II.2. Estudio jurisprudencial. II.3. Idea doctrinal. II.4. Análisis conceptual de invitación a negociar. III. Efectos de las invitaciones a negociar. III.1. Ordenamiento español. III.2. Análisis de sus efectos. IV. Conclusiones. V. Bibliografía. VI. Índice de sentencias citadas.

\section{INTRODUCCIÓN}

El objeto de este artículo es analizar una institución precontractual cada vez más común en la formación de los contratos: las invitaciones a contratar. Este tipo de figura se emplea paulatinamente con más frecuencia en ámbitos que van desde la contratación administrativa al simple arrendamiento de servicios por empresas privadas.

Esta manifestación precontractual se suele utilizar en el primer estadio de formación de los contratos, en el cual una de las partes muestra su interés por iniciar unas negociaciones que pueden concluir con la celebración de un contrato.

Las invitaciones a negociar presentan caracteres interesantes que no han sido habitualmente precisados por la doctrina y la jurisprudencia, como los posibles efectos que pueden originar. Por ello, mediante el estudio que se realizará en el presente artículo se pretende profundizar un poco más en el análisis y configuración de esta figura precontractual recurrente. 


\section{CONCEPTO DE INVITACIONES A NEGOCIAR}

\section{II.1. Regulación normativa}

En primer lugar, tendríamos que señalar que este tipo de figura precontractual, como otras muchas que se suelen emplear dentro del tráfico jurídico, no está regulada. Así, observamos como la normativa a la que se suele referir la doctrina ${ }^{1}$ y la jurisprudencia ${ }^{2}$ para abordar el estudio de las instituciones precontractuales, el artículo 1.451 del Código Civil, regula la promesa de compra y venta. Supuesto bien distinto de una mera manifestación de negociar. Por consiguiente, hay que atender a la conceptualización jurisprudencial y doctrinal para poder concretar en la configuración de esta institución precontractual.

\section{II.2. Estudio jurisprudencial}

Como previamente se ha apuntado, no hay una definición normativa de las invitaciones a negociar. El Tribunal Supremo se ha pronunciado pocas veces sobre el concepto de esta figura. Normalmente la definición jurisprudencial es más implícita que explícita, al resolver asuntos en los que aparecen documentos calificados como letters of intent o cartas de intenciones por las partes ${ }^{3}$. En algunas de esas ocasiones puede observarse como el documento analizado se ajusta a la figura comentada en este artículo ${ }^{4}$.

De las sentencias que resuelven la mayoría de casos donde el documento fue calificado de letter of intent o carta de intenciones ${ }^{5}$, puede inferirse que el Tribunal Supremo no diferencia las cartas de intenciones de otros documentos precontractuales, situando todos ellos

1 Vid. LaSarte ÁlvareZ, C., Contratos. Principios de Derecho Civil III, $13^{\mathrm{a}}$ ed., Madrid-Barcelona, Marcial Pons, 2010, págs. 64 y ss., PUIG BRUTAU, J., Compendio de Derecho Civil, V. II, Barcelona, Bosch, 1997, págs. 315 y ss., HERNÁNDEZ GIL, A., Derecho de Obligaciones, T. 3, Madrid, Espasa Calpe, 1988, págs. 579 y ss., DÍEZ-PICAZO Y PONCE, L., Fundamentos del Derecho Civil Patrimonial, vol. I, 6 a ed., Madrid, Civitas, 2007, pág. 401, ALBALADEJO GARCÍA, Derecho Civil II Derecho de Obligaciones, $13^{\mathrm{a}}$ ed., Madrid, Edisofer, S.L., 2008, págs. 441 y ss.

2 Vid. SSTS de 3 de noviembre 2010 y de 30 septiembre 2011.

3 Cfr. STS de 14 de octubre 1996, donde tangencialmente se alude a una carta de intenciones por la que se otorgaba un aval por parte de una entidad bancaria.

${ }^{4}$ Vid. STS de 30 de marzo 2010.

5 Vid. SSTS de 4 de julio 1991, de 19 de julio 1994, de 3 de junio 1998 y de 11 de abril 2000. 
en el ámbito de los tratos previos, e incluso considerando en algunos casos que son precontratos. Dicha clasificación depende del grado de determinación de los elementos esenciales, del contenido del documento y del comportamiento de las partes.

No obstante, hay una serie de sentencias interesantes. Un pronunciamiento especialmente ilustrativo lo encontramos en la STS de 12 de julio 2011, en la que se trataba de dilucidar los efectos de un folleto publicitario de viviendas sobre plano, considerando que las mismas son invitaciones a negociar o invitatio ad offerendum. Para el Tribunal Supremo dichas invitaciones no constituyen una oferta en sentido estricto, pero sí una oferta publicitaria. Tal conclusión se centraba en el hecho de que el folleto no contenía todos los elementos esenciales para que se pudiera producir una aceptación.

Por consiguiente, la jurisprudencia sí ha diferenciado las invitaciones a negociar stricto sensu y las ofertas contractuales. Así, en algunos pronunciamientos, el Tribunal Supremo (SSTS de 26 de marzo 1993 y de 20 de abril 2001), y las Audiencias Provinciales (SSAP de Zaragoza de 30 de mayo 1992, de Barcelona de 10 diciembre 2002 y de Barcelona de 28 de febrero 2006), entienden que la consideración como oferta requiere que ésta contenga todos los elementos determinantes del contrato, y que sea susceptible de aceptación simple. Es decir, que no sea necesario un nuevo acuerdo para perfeccionar el contrato. Por lo tanto, parece que la jurisprudencia admite una distinción entre una mera invitación a negociar y una oferta.

Sin perjuicio de lo anterior, hay algunos pronunciamientos en la jurisprudencia menor que contemplan un concepto de invitación a negociar coincidente con el propuesto en este estudio. Así, en la SAP de Zaragoza de 30 de mayo 1992 se ventila un asunto sobre la naturaleza jurídica de un anuncio de prensa que decía: «en Alfamen vendo casa centro pueblo, habitar en el día, facilidades, 40.000 mes».

En este asunto la Audiencia Provincial de Zaragoza consideró que el anuncio debe conceptuarse como «una simple invitación a contratar». Tal invitación la entendió como «un acto preparatorio de un posible y futuro contrato». Para alcanzar la referida conclusión, la Audiencia Provincial reparó en que en la redacción del anuncio no se fijaba el elemento esencial del precio de la compraventa. Por ello, el mencionado anuncio «necesitaba una ulterior concreción» y no constituía una oferta completa, definitiva e inequívoca ${ }^{6}$.

${ }^{6}$ A estos efectos se apoya en las SSTS de 22 de mayo 1970 y de 10 de octubre 1980. 
De lo expuesto, podemos colegir que los documentos precontractuales que no pueden definirse como ofertas por no ser completos, definitivos e inequívocos, y que por ende necesitan una mayor concreción, deben de conceptualizarse como una simple invitación a contratar. Aunque de esta configuración se desprendería que prácticamente cualquier acuerdo precontractual sería una «invitación a negociar». Lo cual no se ajusta a la realidad del tráfico jurídico.

De igual manera, en la SAP de Madrid de 24 de noviembre 2005 se analiza una carta unilateral que presuntamente había sido aceptada tácitamente. Dicha carta, según la Audiencia Provincial, contenía términos genéricos que no constituían ni una oferta, por no ser susceptibles de aceptación, ni un contrato por adolecer de los requisitos establecidos en el artículo 1.261 del Código Civil. Según la Audiencia Provincial tal carta únicamente contenía una propuesta que no regulaba aspectos relevantes ${ }^{7}$. En consecuencia, para la Audiencia Provincial de Madrid dicho documento era una propuesta a contratar que se producía dentro de los tratos preliminares.

En sentido similar se pronuncia la SAP de Barcelona de 28 de febrero 2006, en la que una propaganda inmobiliaria fue también considerada como una invitación a negociar por la indeterminación del inmueble del cual se daban unas pocas referencias ${ }^{8}$. Y también la SAP de Albacete de 21 de junio 2008 respecto a comunicaciones para suscribir un convenio de la SGAE ${ }^{9}$.

Consecuentemente, puede concluirse que no hay un verdadero concepto jurisprudencial de invitación a negociar. Pero sí se observa

7 En concreto la carta «se limita a expresar una propuesta acerca de que Construcciones San Martín compraría los solares (dos o tres), que aquella daría a la Gestora una opción de compra de los solares resultantes del Proyecto de Compensación al precio de costo, que la Gestora -formada por DAE y San Martín al 50\%- encargaría a DAE la administración y comercialización con unos honorarios del $2 \%$ sobre el precio de ventas, y que el margen resultante de la operación se repartirá al 50\% con un mínimo garantizado para San Martín de 300 millones de pts». Aspectos que pueden parecer suficientemente concretos. Sin embargo, la Audiencia Provincial matizaba que «no existe referencia a la descripción y precio de los solares, como tampoco respecto de la opción de compra mencionada en la carta, omitiéndose un dato esencial de la misma, como es la determinación de plazo para su ejercicio, cuya existencia es ineludible para la validez de la opción». Cfr. SAP de Madrid de 24 de noviembre 2005.

${ }^{8}$ En concreto la sentencia dice «ático de una casa junto a Paseo Maragall 125m + buhardilla 50m».

9 En este caso la Audiencia Provincial de Albacete consideró que tales invitaciones a negociar no interrumpían el plazo para reclamar las cantidades que la SGAE solicitaba. Lo cual parece ser más una consecuencia del contenido de las propias comunicaciones que de los efectos jurídicos que el citado tribunal estima que hay que asignar a esta figura precontractual. 
que la jurisprudencia diferencia las invitaciones a negociar de los contratos definitivos, de las ofertas y, a veces, de los precontratos.

\section{II.3. Idea doctrinal}

Las invitaciones a negociar no han suscitado gran interés entre la doctrina, siendo pocos los autores que estudian esta figura precontractual. Normalmente su estudio por los diversos autores se ha centrado en su distinción con la oferta ${ }^{10}$. Los que lo hacen, normalmente no emplean una terminología muy precisa, aludiendo indistintamente con la denominación letter of intent a varias figuras precontractuales ${ }^{11}$. En este trabajo se ha preferido el término invitaciones a negociar por parecer más acorde a su contenido: manifestaciones del deseo de iniciar unos tratos preliminares respecto a un posible contrato.

Un primer posicionamiento interesante lo podemos encontrar en los postulados de PUIG BRUTAU ${ }^{12}$. Según este autor, las invitaciones a negociar ${ }^{13}$ se utilizan cuando el inicio de las negociaciones no comienza con una oferta, sino con invitaciones a que otros las formulen. Para este sector doctrinal, un elemento característico de esta figura es que la parte que plantea la invitación se reserva la facultad de aceptación de las proposiciones que pueda recibir. Sin perjuicio de lo anterior, PUIG BRUTAU puntualiza que habrá que tener en cuenta las circunstancias de cada caso para comprobar si nos encontramos ante una efectiva oferta o ante una declaración dirigida a provocarla. A este respecto, el citado autor considera como ejemplos claros que no constituyen ofertas la exposición de artículos al público con indicación del precio o las manifestaciones contenidas en catálogos ${ }^{14}$.

Es interesante comentar que PUIG BRUTAU ${ }^{15}$ distingue las «invitaciones a presentar ofertas» de las «ofertas con cláusulas "sin com-

10 Vid. PUIG BRUTAU, op. cit., págs. 217 y 218.

11 Cfr. LLODRÀ GRIMALT, F., "Letter of intent, carta de intenciones, precontrato", en Derecho de los negocios, n ${ }^{\circ}$ 151, abril 2003, pág. 15; SIMÓ SEVILLA, S. y otros, Instituciones de Derecho Privado, T. III, vol. 2 ${ }^{\circ}$ Madrid, Civitas, 2005, pág. 336; CARRASCO PERERA, A., «Las Cartas de Intenciones» en Fusiones y Adquisiciones de Empresas, Cizur Menor, Navarra, Thompson Aranzadi, 2004, pág. 88.

12 Cfr. op. cit., págs. 217 y ss.

13 Aunque PUIG BRUTAU usa la denominación de «invitaciones a presentar ofertas».

${ }_{14}$ En ambos casos por criterios de justicia material y por sus efectos prácticos.

15 Cfr. op. cit., pág. 218. 
promiso" ${ }^{16}$, en el sentido que las últimas obligan al destinario que las acepta, pero no al oferte que las formula.

De manera similar se pronuncian otros autores como LASARTE ÁLVAREZ ${ }^{17}$, para el cual las «invitaciones a contratar» requieren de posteriores precisiones del destinatario, y por consiguiente no pueden ser consideradas ofertas, al no disponer de todos los elementos necesarios para que pueda producirse la perfección del contrato.

En la misma línea, MENÉNDEZ MATO llama a esta figura precontractual "oferta a negociar» ${ }^{18}$, definiéndola como «una propuesta realizada por un sujeto a otro que la acepta, cuyo contenido consiste en una proposición no de conclusión, sino de diálogo, de negociación - sin fuerza vinculante- acerca de un futuro eventual contrato» ${ }^{19}$. Es decir, es una proposición de iniciar los tratos previos ${ }^{20}$. El anverso de la "oferta a negociar» sería la «invitación a realizar ofertas», que conforme a este autor ésta "consiste en la solicitud, que una parte realiza a la otra, de que le comunique una oferta contractual del tipo que sea, con el fin de conocer sus intereses» ${ }^{21}$. Ambas figuras serían distintas de una oferta, puesto que carecen de los elementos del contrato definitivo y de la voluntad de contratar ${ }^{22}$. Al respecto tendríamos que precisar que ambas instituciones podrían ser consideradas invitaciones a negociar a efectos de este estudio, puesto que encajan dentro del concepto propuesto.

Para MENÉNDEZ MATO, esta figura precontractual tiene por finalidad «informar/se, discutir, cooperar, asegurar, ofrecer y, como fin último, concluir un futuro contrato ${ }^{23}$. Igualmente interesante a efectos de este artículo es que el referido autor ${ }^{24}$ precise que estas invitaciones a negociar no pueden identificarse con el precontrato, el contrato de opción o el acuerdo de intenciones, ya que dichas instituciones precontractuales no pueden suponer el inicio de los tratos preliminares.

16 Para lo cual siguiendo al citado autor en Derecho comparado se usan cláusulas como sans engagement, senza impegno, freibleibend o not binding. 372.

17 Cfr. Curso de Derecho Patrimonial, 16 a ed., Madrid, Tecnos, 2010, págs. 371 y

18 Cfr. La Oferta Contractual, Pamplona, Aranzadi, 1998, pág. 91.

9 Cfr. MENÉNDEZ MATO, J. C., La oferta..., op. cit., pág. 85.

Cfr. MENÉNDEZ MATO, J. C., La oferta..., op. cit., pág. 91.

1 Cfr. La oferta..., op. cit., pág. 91.

2 Cfr. MENÉNDEZ MATO, J. C., La oferta..., op. cit., pág. 91.

3 Cfr. op. cit., pág. 84.

4 Cfr. op. cit., pág. 84. 
Por su parte, LLODRÀ GRIMALT ${ }^{25}$ entiende que las letters of intent son invitaciones a negociar no susceptibles de aceptación. Consecuentemente no son ofertas, sino documentos unilaterales dirigidos a que otros formulen ofertas o a iniciar negociaciones.

Dentro de las diversas configuraciones que Carrasco PERERA emplea respecto a las «cartas de intenciones» o letters of intent se encuentran los documentos unilaterales o bilaterales en los que una o ambas partes de una negociación declaran su compromiso/intención/deseo/oferta de comenzar o continuar una negociación que acabe con un acuerdo definitivo de compra ${ }^{26}$.

A su vez, es interesante comentar que otros autore ${ }^{27}$ consideran $^{2}$ esta figura como una «oferta simple», que se diferencia de la «oferta vinculante» en dos aspectos. El primero es que la oferta simple no contiene todos los elementos del futuro contrato, por lo que no puede ser objeto de aceptación. El segundo es que la intención de la oferta vinculante es de contratar, mientras que la voluntad de la oferta simple consiste en iniciar la negociación o "ánimo de tratar», en vez de «ánimo de contratar».

En sentido similar se pronuncia ALBALADEJO GARCÍA ${ }^{28}$, para el cual las invitaciones a ofrecer o contratar preceden a la oferta y consisten en un simple anuncio de deseo de contratar, solicitando que los destinatarios del mismo comuniquen las condiciones en que éstos estarían dispuestos a contratar.

Todos los autores parecen coincidir en que las invitaciones a negociar son documentos que recogen una manifestación de un interés en negociar ${ }^{29}$. Por consiguiente, son actos previos a los tratos preliminares, cuya única finalidad es plasmar esa voluntad de $\operatorname{tratar}^{30}$.

A este respecto es interesante indicar que Carrasco PERERA puntualiza que una letter of intent, como su propio nombre indica, tiene forma de carta. Por lo tanto, es un documento que prima facie es re-

${ }^{25}$ Cfr. op. cit., pág. 15.

${ }^{26}$ Cfr. «Las Cartas de Intenciones» en Fusiones y Adquisiciones de Empresas, op. cit., pág. 88.

${ }_{27}$ Cfr. LOBATO DE BLAS, J., «Consideraciones sobre el concepto de tratos preliminares» en Revista General de Legislación y Jurisprudencia, nº 6 diciembre 1976, págs. 564 a 566, siguiendo a numerosos autores como CARBONNIER o GORLA.

${ }_{28}$ Cfr. op. cit., págs. 376.

29 Cfr. CAVESTANY, J., "Letters of intent, precontratos y otros acuerdos preparatorios» en Expansión jurídico 7 de junio 2010, accesible en http://www.expansion.com/accesible/2010/06/07/juridicoopinion/1275925551.html.

${ }^{30}$ Cfr. LOBATO DE BLAS, J., op. cit., págs. 541 a 566. 
dactado por una parte, con la consecuente asimilación jurídica que puede hacerse respecto a un contrato de adhesión ${ }^{31}$. Como el citado autor comenta, las consecuencias prácticas de tal adhesión no son sustanciales, puesto que las invitaciones a negociar no se suelen suscribir con consumidores. Aunque puede indicarse algún efecto al respecto, como la aplicación del artículo 1.288 del Código Civil, por el cual los términos oscuros no pueden beneficiar a quien los redactó. Por consiguiente, esta consecuencia sería aplicable a las invitaciones a negociar que tengan forma de carta, lo cual es habitual dentro del tráfico jurídico.

Consecuentemente, conforme a la doctrina española las invitaciones a negociar serían documentos unilaterales susceptibles de aceptación, cuyos rasgos característicos son, por un lado, la intención de una de las partes de tratar, y no de vincularse ${ }^{32}$; y por otro, que este documento no contenga todos los elementos del contrato que se pretende celebrar ${ }^{33}$. Por tanto, la aceptación no conlleva la perfección del posible contrato ${ }^{34}$, sino simplemente la asunción de los condicionantes de dicha voluntad de tratar que están recogidos en la invitación a negociar ${ }^{35}$.

\section{II.4. Análisis conceptual de invitación a negociar}

Conforme a lo expuesto, podría concluirse que las invitaciones a negociar son simplemente una manifestación de voluntad unilateral de iniciar la negociación de un contrato. Tal expresión de voluntad suele manifestarse en forma de carta, en la que su contenido rele-

31 Cfr. CARRASCO PERERA, A., "Las Cartas de Intenciones» en Fusiones y Adquisiciones de Empresas, op.cit., pág. 90.

32 Cfr. PUIG BRUTAU, J., op. cit., pág. 217.

${ }_{33}$ Cfr. LASARTE ÁlVAREZ, C., Curso de Derecho Patrimonial, op. cit., págs. 371 y 372. De forma similar, CARRASCO PERERA considera que los términos del contrato proyectado solo aproximadamente se identifican. Cfr. «Las Cartas de Intenciones» en Fusiones y Adquisiciones de Empresas, op. cit., pág. 89.

${ }^{34}$ Cfr. LLODRÀ GRIMALT, F., op. cit., pág. 15, PUIG BRUTAU, J., op. cit., pág. 217, entre otros.

35 A este respecto CARRASCO PERERA contempla dos causas para dicha ausencia de perfección del contrato proyectado. Una es la gran indeterminación respecto a los términos del contrato proyectado. Otra es la habitual clarificación de las partes de que no quieren quedar vinculadas. Cfr. "Las Cartas de Intenciones» en Fusiones y Adquisiciones de Empresas, op. cit., pág. 90 . En el caso de una letter of intent conforme al concepto propuesto de invitación a negociar en este artículo, habría que añadir que tal letter of intent únicamente inicia, en el caso de que sea aceptada, los tratos preliminares. En consecuencia, ninguna perfección de contrato puede tener lugar. 
vante aparece como una declaración de una parte que requiere ser suscrita por su destinatario ${ }^{36}$. Es decir, éstas son la expresión del deseo de una parte de que comiencen los tratos preliminares del contrato proyectado ${ }^{37}$; y es que los tratos preliminares sólo nacerían si el destinatario expresa su voluntad de negociar. Tal manifestación de voluntad se produce precisamente con la respuesta positiva o aceptación de la invitación a negociar. Aunque es frecuente que la aceptación se solicite y consecuentemente se encuentre en el mismo documento, por lo que las invitaciones a negociar constituirían en esos casos el inicio de los tratos preliminares.

En efecto, siguiendo el concepto de inicio de tratos preliminares (vorverhandlungen, trattative) propuesto por DÍEZ-PICAZO Y PON$\mathrm{CE}^{38}$, MENÉNDEZ MATO ${ }^{39}$ y ALBALADEJO GARCÍA ${ }^{40}$, comprobamos cómo con la aceptación de la invitación a negociar concurren los elementos comentados por ellos. Así, habría por un lado una referencia a un futuro contrato para iniciar las discusiones sobre él, y por otro, mediante la suscripción de la invitación a negociar se pondrían en contacto los sujetos de la negociación.

Las meras invitaciones a negociar sí existen en el tráfico jurídico. De hecho, éstas son una forma habitual de iniciar una negociación. Sobre todo cuando una de las partes quiere entrar en contacto con más de un posible contratante para saber qué oferta le puede resultar más provechosa. Ejemplos de esta forma de empezar las negociaciones los encontramos en la venta de empresas que se realiza mediante una subasta entre diversos compradores, o en las request for information $^{41}$ que utilizan las administraciones públicas o las concesionarias para iniciar una licitación, o, incluso más profanamente, en la contratación de arrendamientos de servicios cuando se pide presu-

\footnotetext{
${ }^{36}$ Cfr. CARRASCO PERERA, A., "Las Cartas de Intenciones» en Fusiones y Adquisiciones de Empresas, op. cit., pág. 91.

37 Concepto similar al utilizado en Francia respecto a las cartas de interés (lettre d intérêt), que se utilizan para mostrar interés en el proyecto, cfr. FABRE-MAGNAN, M., Les obligations, Francia, Presses Universitaires de France, 2004, pág. 214.

${ }^{38}$ En concreto, este autor señala que son «los actos que los interesados y sus auxiliares llevan a cabo con el fin de elaborar, discutir y concertar el contrato». Dentro de este concepto se incluiría también las «manifestaciones escritas, redacción de proyectos, minutas o borradores». Cfr. Fundamentos..., $6^{\text {a }}$ ed., op. cit., pág. 311.

39 Cfr. op. cit., págs. 83 y 84.

40 Cfr. op. cit., pág. 377, para el que en sentido amplio los tratos preliminares incluirían la discusión sobre la oferta y posibles contraofertas, hasta que se alcance el acuerdo o se rompa la negociación.

${ }^{41}$ Que significa solicitud de información.
} 
puesto a distintos profesionales del mismo ramo como pintores, fontaneros, abogados, etcétera.

Por tanto, las manifestaciones de intención de tratar son comunes en la práctica, aunque no sean objeto de un estudio concienzudo por la doctrina y la jurisprudencia. Ello conlleva que se haya creado una figura precontractual que responda a esta necesidad del tráfico jurídico. En consecuencia, parece oportuno que tal institución exista para concretar sus efectos, diferenciándolos de los asignados a los tratos preliminares y a otras figuras precontractuales.

En ese sentido, parece acertada la posición doctrinal descrita de estimar que hay una figura previa a los tratos preliminares, cuya única finalidad es el darle inicio. Por consiguiente, en este análisis se postula un concepto de invitación a negociar con las siguientes características:

a) Es un documento privado que no recoge una voluntad de contratar ni de vincularse por parte de quien lo emite ${ }^{42}$.

b) Constituye una manifestación unilateral de querer iniciar unas negociaciones, en la que se describe el tipo de contrato proyectado $^{43}$, y en algunos casos, determinados aspectos suyos, como su objeto o el plazo de inicio. Pero las invitaciones a negociar no precisan más aspectos del futuro contrato, porque éstos deberán ser negociados. A veces las invitaciones a negociar pueden contener la aceptación del destinatario, constituyendo el inicio de los tratos preliminares.

c) Es una figura autónoma del contrato proyectado y de otros acuerdos precontractuales que pueden suscribirse durante las negociaciones.

\section{EFECTOS DE LAS INVITACIONES A NEGOCIAR}

\section{III.1. Ordenamiento español}

Las invitaciones a negociar no están reguladas en Derecho español como se ha expuesto anteriormente. Por ello, el estudio de la

${ }^{42}$ En este sentido, MENÉNDEZ MATO, siguiendo a diversa doctrina y jurisprudencia, comenta que habría que distinguir entre el interés jurídico de las partes sobre un futuro contrato y la intención de contratar. Para este autor, en consonancia con lo explicado en este artículo, esta fase precontractual estaría determinada por el contacto de los intereses de las partes. Cfr. La oferta..., op. cit., pág. 84.

${ }^{43}$ Cfr. ALBALADEJO GARCÍA, M., op. cit., pág. 376. 
eficacia de las invitaciones a negociar se va a realizar en un solo apartado teniendo en cuenta las únicas fuentes disponibles a falta de regulación: la jurisprudencia y la doctrina.

Las invitaciones a negociar difieren de las ofertas en sentido estricto en que no recogen una voluntad de contratar, y en que no son susceptibles de una simple aceptación ${ }^{44}$.

En efecto, siguiendo a MENÉNDEZ MATO, puede decirse que una oferta es un acto de la fase precontractual consistente en «una declaración unilateral y recepticia portadora de una específica voluntad: la intención firme de concluir un determinado contrato ${ }^{45}$. De igual manera se pronuncian otros muchos autores ${ }^{46}$. Así, LACRUZ $\mathrm{BERDEJO}^{47}$ comenta que la oferta «tiene que ser precisa, completa y definitiva y revelar inequívocamente el propósito de vincularse contractualmente del autor de la misma». Por consiguiente, en la oferta el oferente manifiesta su intención de vincularse contractualmente en las condiciones estipuladas en ella. Sin embargo, las invitaciones a negociar recogen unas declaraciones de una parte, en las cuales se expresa una voluntad de iniciar unas negociaciones encaminadas a la celebración de un contrato. Contrato del que habitualmente solo se esbozará su objeto, dejando indeterminadas el resto de sus condiciones.

Esto quiere decir que, a diferencia de lo que ocurre con una oferta en sentido estricto, no se produce una mayor determinación del contenido del contrato que se quiere celebrar porque en este caso no se persigue la aceptación ${ }^{48}$, y por tanto, el in idem placitum $^{49}$. La mayor concreción se producirá en la posterior negociación del contrato proyectado. En este sentido es clarificadora la STS de 7 de junio 1986 al señalar que «no existe acuerdo de voluntades cuando solo me-

${ }_{44}$ Cfr. SSTS de 26 de marzo 1993 y de 20 de abril 2001; SSAP de Zaragoza de 30 de mayo 1992, de Barcelona de 10 de diciembre 2002 y de Barcelona de 28 de febrero 2006. En igual sentido se pronuncia la doctrina. Cfr. BELTRÁN SÁNCHEZ, E., ORDUÑA MORENO, F. J. y otros, Curso de Derecho Privado, $13^{\mathrm{a}}$ ed., Valencia, Tirant lo Blanch, 2010, pág. 217, PUIG BRUTAU, J., op. cit., pág. 217.

${ }^{45}$ Cfr. op. cit., pág. 24.

${ }^{46}$ Cfr. LASARTE ÁlvareZ, C., Curso de Derecho Patrimonial, op. cit., pág. 371, MARTÍN BERNAL, J. M., Nociones de Derecho Patrimonial, Madrid, Editorial Centro de Estudios Ramón Areces, S.A., 2003, pág. 358, PUIG BRUTAU, J., op. cit., pág. 215.

${ }^{47}$ LACRUZ BERDEJO, J. L., Nociones de Derecho Civil Patrimonial e introducción al Derecho, $4^{\mathrm{a}}$ ed., Madrid, Dykinson, 2004, pág. 281.

${ }^{48}$ Cfr. SAP de Zaragoza de 30 de mayo 1992, DÍEZ-PICAZO Y PONCE, L., Fundamentos..., págs. 330 y ss.

49 Cfr. CARRASCO PERERA, A., "Las Cartas de Intenciones» en Fusiones y Adquisiciones de Empresas, op. cit., pág. 90. 
dia la manifestación de un propósito retirado por su autor antes de ser aceptado por la otra parte».

Consecuentemente, las invitaciones a negociar no pueden producir los mismos efectos que el contrato proyectado. En ese sentido, también se ha pronunciado la jurisprudencia menor, como la SAP de Madrid de 24 de noviembre 2005. Sentencia que, siguiendo un concepto de invitación a negociar similar al propuesto en este estudio, llega a la conclusión de que únicamente podría generar responsabilidad extracontractual. Responsabilidad que obligaría a indemnizar el daño emergente de los costes de la negociación.

Según lo expuesto, las invitaciones a negociar se caracterizan por ser una vaga invitación a $\operatorname{tratar}^{50}$, en ocasiones aceptada en el mismo documento, donde suele concretarse el tipo de contrato, las partes, y a lo sumo el objeto del contrato proyectado. Por tanto, los aspectos contemplados en la invitación a negociar son susceptibles de modificación por posteriores acuerdos precontractuales o por el contrato definitivo ${ }^{51}$.

Conforme a dicho concepto, es interesante precisar que la aceptación de las invitaciones a negociar supondría el inicio de los tratos preliminares $^{52}$, puesto que en el mismo documento se ha producido la manifestación de negociar del receptor ${ }^{53}$. Por ello, con su aceptación nacerían los derechos y obligaciones propios de esta fase de preparación del contrato, como el deber de actuar de buena fe. Este sería su principal efecto, aunque conviene analizar si pueden producirse otros. Siguiendo a DÍEZ-PICAZO Y PONCE ${ }^{54}$, podríamos indicar que aunque entre los negociadores no hay una verdadera relación jurídica por la aceptación de la invitación a negociar, el inicio de los tratos preliminares sí conlleva:

a) Un deber de negociar de buena fe.

b) Una obligación de proporcionar determinadas informacio-

${ }^{50}$ Cfr. CAVESTANY, J., op. cit.

51 Cuestión obvia que ha sido abordada por alguna sentencia, como la SAP de Zaragoza de 30 de mayo 1992.

52 Vid. LACRUZ BERDEJO. J.L., op. cit., pág. 285, LASARTE ÁlVAREZ, C., Curso de Derecho Patrimonial, $16^{\mathrm{a}}$ ed., Madrid, Tecnos, 2010, pág. 373.

53 Cfr. LLODRÀ GRIMALT ,F., op. cit., pág. 15 y SAP de Vizcaya de 13 de octubre 2000. Con la aceptación de la invitación a negociar se abriría, en palabras de MENÉNDEZ MATO, el período tendente «a que se produzca la perfecta fusión de la oferta y la aceptación», que lo denomina genéricamente como "fase precontractual» o "fase de formación del contrato». Cfr. La oferta..., op. cit., pág. 24.

${ }^{54}$ Cfr. Fundamentos..., op. cit., pág. 312. 
nes. La determinación de las mismas se realiza según el citado autor conforme a los criterios de buena fe y los usos de los negocios. Aunque también se remite al artículo 4.107 PECL ${ }^{55}$, en el que se citan una serie de supuestos en los que se infringiría el mencionado precepto.

c) Un deber de protección.

d) Una obligación de confidencialidad. A este respecto DÍEZ-PICAZO Y PONCE recuerda que no existe un deber especial de confidencialidad. Para determinar su existencia, el citado autor propone atender al carácter confidencial de la información que provenga de una declaración expresa o que derive tácitamente de las circunstancias. Asimismo, es especialmente interesante que según este autor el citado deber no solo incluye el hecho de no divulgar a terceros la información confidencial, sino también el no utilizar dicha información en beneficio propio ${ }^{56}$.

Sin perjuicio de lo anterior, habría que comentar que al igual que las ofertas, éstas son invitaciones que se pueden retirar sin originar responsabilidad alguna ${ }^{57}$. Por ello podría actuarse posteriormente de forma contraria a lo señalado en dicha invitación ${ }^{58}$. Siempre, claro está, que la invitación a negociar no haya sido aceptada. Esta apreciación parte de la premisa de que las invitaciones a negociar no son «ofertas propiamente dichas», sino «simples ofertas» o «meras invitaciones a ofrecer» en terminología de LOBATO DE BLAS ${ }^{59}$. Conforme se ha explicado, las invitaciones a negociar carecen de intención de contratar y no contienen todos los elementos del contrato proyecta$\mathrm{do}^{60}$, por lo que difícilmente pueden generar responsabilidad alguna.

$\mathrm{Al}$ respecto conviene recordar que las invitaciones a negociar pueden, a lo sumo y si son aceptadas, suponer el comienzo de los tratos preliminares, por lo que difícilmente pueden crear una legítima expectativa de conclusión del contrato definitivo. Aunque hay que matizar que la revocación sí puede suponer una ruptura injustificada de las negociaciones en el caso de que la invitación a negociar haya

55 Acrónimo en inglés que responde a la denominación Principles of European Contract Law, que suele traducirse por Principios europeos de Derecho contractual.

${ }^{56}$ Cfr. Fundamentos..., op. cit., pág. 314.

57 Cfr. PUIG BRUTAU, J., op. cit., pág. 217.

$58 \mathrm{Vid}$. STS de 16 de septiembre de 2004, respecto a una invitación a negociar dirigida a un sindicato, que fue rechazada por el sindicato. Conclusión de la jurisdicción social que parece plenamente extrapolable a la jurisdicción civil.

59 Cfr. LOBATO DE BLAS, J., op. cit., págs. 541 a 582.

60 Es decir, no cumplen la exigencia de que la oferta «contenga todos los elementos determinantes del objeto y causa», sin que quepa «introducir modificación alguna que requiera un nuevo acuerdo». Cfr. SSTS 26 de marzo 1993 y de 20 de abril 2001. 
sido aceptada. No obstante, el carácter injustificado no genera automáticamente responsabilidad precontractual ${ }^{61}$. Para ello, deben de concurrir los requisitos que se expondrán más adelante. A este respecto hay que indicar siguiendo a parte de la doctrina, que la responsabilidad precontractual derivada de la ruptura injustificada de las negociaciones no tiene sustantividad propia $^{62}$, por lo que se entiende generalmente que tiene su origen en la responsabilidad extracontractual prevista en el artículo 1.902 del Código Civil o en la obligación de negociar de buena fe contemplada en los artículos 1.258 y 7.1 del Código Civil ${ }^{63}$. Aunque algunos autores parecen optar claramente por la responsabilidad extracontractual ${ }^{64}$.

Por otro lado, en nuestro Derecho existe un principio general de li-

${ }^{61}$ Cfr. ALBALADEJO GARCÍA, M., op. cit., pág. 377; TERSILLA, S., «La lettera di intenti nella trattativa per l acquisizione di un pacchetto azionario di riferimento» en Diritto del Comercio Internazionale, v. 17, 2003, pág. 521.

${ }^{62}$ Así, siguiendo a MENÉNDEZ MATO, habría que concluir que el término más apropiado, si no hay acuerdo precontractual que contemple la obligación de negociar, es responsabilidad extracontractual, puesto que la responsabilidad precontractual o culpa in contrahendo carece de entidad propia. En concreto, el citado autor comenta: «el concepto de «responsabilidad precontractual» o por «culpa in contrahendo» no encuentra su definición directamente en uno u otro tipo de responsabilidad civil, sino en el concepto que se adopte de fase precontractual. Si esta última es concebida en sentido restrictivo -como el período que antecede a todo contrato, no diferenciándose entre los definitivos y los instrumentales-, la llamada "culpa in contrahendo"se identificará con la típica responsabilidad extracontractual. Sin embargo, adoptando un concepto amplio de fase precontractual -como el llevado a cabo en el presente trabajo-, la "culpa in contrahendo» podrá ser de tipo extracontractual o contractual, dependiendo de la naturaleza del concreto acto en el que se produzcan los daños resarcibles. Por esta razón, lo importante es la correcta calificación del tipo de responsabilidad extracontractual o contractual presente en cada caso -al poseer ambas dos regímenes diferentes-, y no el empleo de una categoría que, como la denominada «responsabilidad precontractual», carece de un régimen propio e independiente de los anteriores». (Cfr. La oferta..., op. cit., págs. 100 y 101).

${ }^{63} \mathrm{Vid}$. LACRUZ BERDEJO, J. L., op. cit., pág. 285, LASARTE ÁLVAREZ, C., Contratos. Principios de Derecho Civil III, op. cit., pág. 63.

${ }^{64}$ Cfr. BELTRÁN SÁNCHEZ, E., ORDUÑA MORENO, F. J. y otros, op. cit., pág.

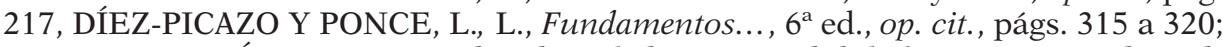
CABANILLAS SÁNCHEZ, A., «El ámbito de la responsabilidad precontractual o culpa in contrahendo» en Revista Crítica de Derecho Inmobiliario, $\mathrm{n}^{\circ}$ 628, Mayo-Junio 1995, págs. 764 y 765; MORENO QUESADA, B., La oferta de contrato. Génesis del contrato y responsabilidad antecontractual. Doctrina, legislación, comentarios, jurisprudencia, Colección Nereo, Barcelona, 1963, pág. 45, LASARTE ÁLVAREZ, C., Contratos. Principios de Derecho Civil III, op. cit., pág. 94. Aunque hay autores que defienden que no se encuentra dentro del ámbito de aplicación del artículo 1.902 del Código Civil, porque no es exigible la concurrencia de la culpa. Cfr. MEDINA ALCOZ, M., «La ruptura injustificada de los tratos preliminares: notas acerca de la naturaleza de la responsabilidad precontractual», en Revista Crítica de Derecho Inmobiliario n ${ }^{\circ}$ 5-6/2005, Mayo-Junio 2005, págs. 78 y ss. 
bre revocabilidad de las ofertas ${ }^{65}$. Aunque algunos autores precisan que parece necesario entender que en todo caso debería mantenerse la oferta un tiempo mínimo para que el destinatario pueda comprobar si le conviene aceptar ${ }^{66}$. Esta libertad sólo se ve cercenada por el carácter irrevocable de la oferta. Pero las invitaciones a negociar no son irrevocables, puesto que únicamente suponen una declaración unilateral de voluntad de iniciar unas negociaciones sobre un contrato proyectado. Esa voluntad es revocable, y no puede ser fuente de obligación o responsabilidad alguna conforme a nuestra doctrina ${ }^{67}$.

Los autores son reacios a considerar que las ofertas no irrevocables pueden generar obligación o responsabilidad alguna ${ }^{68}$; aunque algunos como GARCÍA RUBIO siguiendo a MORENO QUESADA, admitan que a veces sí pueda originarse. Son fundamentalmente los casos en los que la parte a la que iba dirigida la oferta haya iniciado de buena fe la ejecución del contrato expuesto en la oferta. Estos supuestos no tienen un respaldo normativo expreso, y la doctrina se apoya en la protección de la buena fe y la sanción del abuso de derecho para sostener esta responsabilidad.

Esta postura sobre las ofertas revocables no parece sostenible respecto a las invitaciones a negociar. Esencialmente porque el supuesto principal al que se aplica no se puede producir con las invitaciones a negociar ${ }^{69}$. Una simple manifestación de voluntad de inicio de negociaciones no puede desencadenar el comienzo de la ejecución de un contrato de buena fe. Si acaso, una ejecución de mala fe con la intención de vincular a una parte a un contrato que no se ha celebrado, puesto que ni lo ha consentido, ni hay un objeto suficientemente determinado, ni se ha fijado una contraprestación por la ejecución.

Por otro lado, no parece que haya supuestos que se puedan am-

${ }^{65}$ Cfr. Lasarte Álvarez, C., Contratos. Principios de Derecho Civil III, op. cit., pág. 56, MARTIN BERNAL, J. M., op. cit., pág. 358, DÍEZ-PICAZO Y PONCE, L., Fundamentos..., págs. 341 y ss.

${ }^{66}$ Cfr. PUIG BRUTAU, J., op. cit., pág. 219.

${ }^{67}$ Cfr. GARCÍA RUBIO, M. P., La responsabilidad precontractual en el ordenamiento español, $1^{\mathrm{a}}$ ed., Madrid, Tecnos, 1991, pág. 145.

${ }_{68}$ Cfr. GARCÍA RUBIO, M. P., op. cit., págs. 146 a 150

69 Supuesto distinto sería una orden o pedido en virtud de un contrato previamente celebrado. Exteriormente ambos documentos podrían tener alguna semejanza, mas hay una diferencia fundamental: en un caso sí se ha celebrado un contrato, y por ello la orden o pedido no reproduce las condiciones, ya que éstas son las del contrato. Sin embargo, con las invitaciones a negociar no hay contrato y no hay posibilidad de determinar las vaguedades del documento. 
parar en la buena fe o en el abuso de derecho para generar responsabilidad u obligación alguna. La mera manifestación de voluntad de inicio de negociaciones puede generar unas legítimas expectativas de que éstas comiencen; pero no un derecho, al no ser fuente de obligaciones la mera manifestación sin voluntad de obligarse conforme a los artículos 1.089 y 1.090 del Código Civil. No obstante, hay algún pronunciamiento dentro de la jurisprudencia menor que ha admitido tal posibilidad, seguramente debido a la concreción de la propuesta ${ }^{70}$.

Como consecuencia de las expectativas generadas por una invitación a negociar pueden realizarse algunos comportamientos de buena fe, que pueden acarrear gastos. Gastos que no pueden ser elevados, ya que el inicio de unas negociaciones no debería implicar desplazamientos, sino comunicaciones en tal sentido. Debido a la irrelevancia de los gastos y a que éstos difícilmente serían imputables a la otra parte, puesto que el riesgo de que ese inicio de la negociación no finalice en la conclusión del contrato proyectado debería ser asumido por cada parte, no parece que las invitaciones a negociar puedan generar daños. Y ello porque no concurrirían los requisitos necesarios para que surja la responsabilidad extracontractual.

En este sentido parece manifestarse también la doctrina ${ }^{71}$ y la jurisprudencia ${ }^{72}$, pues este tipo de responsabilidad se origina principalmente por la ruptura injustificada de las negociaciones ${ }^{73}$. Así, LASARTE ÁLVAREZ ${ }^{74}$ ilustrativamente comenta que «la parte que hubiere negociado o roto las negociaciones de manera contraria a las exigencias de la buena fe, será responsable de las pérdidas causadas a la otra parte». Algunos autores incluso señalan que esta responsabilidad es de carácter objetivo, requiriendo que una parte

${ }^{70}$ Cfr. SAP de Madrid de 24 de noviembre 2005.

71 Cfr. LLODRÀ GRIMALT, F., op. cit., págs. 15 y ss.; SIMÓ SEVILLA, S., y otros, op. cit., págs. 336 y 337; CARRASCO PERERA, A., "Cartas de intenciones, precontratos, responsabilidad in contrahendo y obligatoriedad de los tratos en la jurisprudencia española» en Aranzadi Civil, vol. III, 2005, págs. 2371 y ss.; CAVANILLAS MÚGICA, S., «Sentencia de 14 de junio de 1999: responsabilidad por ruptura de tratos preliminares», en Cuadernos Civitas de Jurisprudencia Civil, n ${ }^{\circ}$ 51, 1999, págs. 1156 y ss.; PASCUAL ESTEVILL, L., Derecho de daños, T. II, $2^{\mathrm{a}}$ ed., Barcelona, Bosch, 1995, págs. 1023 y ss.

72 Cfr. STS de 14 de junio 1999.

73 Cfr. ALBALADEJO GARCÍA, M., op. cit., págs. 377 a 380; ASÚA GONZÁLEZ, C. I., La culpa in contrahendo, Erandi, Servicio Editorial Universidad del País Vasco, 1989, págs. 152 a 163; PASCUAL ESTEVILL, L., op. cit., págs. 1096 y ss. y GARCÍA RUBIO, M. P., op. cit., págs. 130 a 133; SSTS de 7 de junio 1986, de 19 de julio 1994 y de 13 de octubre 2005, SAP de León de 8 de febrero 2002.

${ }^{74}$ Cfr. Contratos. Principios de Derecho Civil III, op. cit., pág. 64. 
haya obrado de mala fe, ofreciendo algo que no le pertenecía o sin tener voluntad real de negociar ${ }^{75}$. Supuesto que no puede ocurrir exclusivamente por la suscripción de una invitación a negociar, y sí por la continuación de los tratos preliminares, que requieren una actividad mayor que la celebración de la invitación a negociar. Además, conviene recordar que las invitaciones a negociar aceptadas suponen el inicio de los tratos preliminares, por lo que difícilmente puede originarse una culpa in contrahendo, y menos responsabilidad contractual ${ }^{76}$.

A su vez, es interesante señalar que varios autores no prevén a priori limitación alguna en la obligación de reparar los daños causados en los casos anteriormente mencionados ${ }^{77}$.

Por tanto, puede concluirse que las invitaciones a negociar no pueden generar, por regla general, obligación o responsabilidad alguna en el Derecho español ${ }^{78}$. Sin embargo, siguiendo algunos postulados doctrinales y jurisprudenciales, parece que si habría que entender que pueden generar otro tipo de consecuencias jurídicas, como servir de criterio integrador del contrato posterior conforme al artículo 1.258 del Código Civil ${ }^{79}$.

\section{III.2. Análisis de sus efectos}

Según el concepto propuesto en este análisis, las invitaciones a negociar son declaraciones unilaterales que muestran el interés en ini217.

${ }^{75}$ Cfr. BELTRÁN SÁNCHEZ, E., ORDUÑA MORENO, F. J. y otros, op. cit., pág.

${ }^{76}$ Especialmente ilustrativas en este sentido son las SSTS de 11 de marzo 1988 y de 13 de diciembre 1989 al comentar: «Las conversaciones previas y proyectos no llegaron a concretarse ni en definitiva recayó sobre los mismos la total aquiescencia de las partes, no existiendo al respecto verdadera prestación de consentimiento con la finalidad expresa de obligarse mutuamente en virtud de un vínculo jurídico efectivo y real, no llegando a nacer siquiera el contrato preliminar, razón que impide derivar de ello daños y perjuicios, pues lo manifestado por una parte no vincula a la otra mientras no lo reciba y pacte de consuno».

77 Cfr. BELTRÁN SÁNCHEZ, E., ORDUÑA MORENO, F. J. y otros, op. cit., pág. 217, LASARTE ÁlVAREZ, C., Contratos. Principios de Derecho Civil III, op. cit., pág. 64.

$78 \mathrm{Vid}$. STS de 22 de diciembre 2010, que entiende que no hay responsabilidad de una aseguradora por no atender las invitaciones de una asegurada de un seguro de defensa jurídica a participar en el litigio y en la negociación transaccional. De igual manera se pronuncia la STS de 30 de junio 2005, respecto a los efectos de carta de patrocinio, porque entiende que supone algo más que una mera invitación o incitación.

${ }^{79}$ Cfr. STS de 12 de julio 2011. 
ciar unas negociaciones. Como tales, las invitaciones a negociar no pueden producir una eficacia contractual, ya que según el artículo 1.261 del Código Civil estos acuerdos precontractuales no son contratos. En efecto, si se examina la configuración propuesta puede observarse cómo en la invitación a negociar no hay un consentimiento, puesto que es un documento unilateral. En sentido similar se pronuncia parte de la doctrina española, como CARRASCO PERE$\mathrm{RA}^{80}$.

Según el precepto 1.089 del Código Civil: «las obligaciones nacen de la ley, de los contratos y cuasicontratos y de los actos u omisiones ilícitos o en que intervengan cualquier género de culpa o negligencia». Más concretamente, el artículo 1.902 del Código Civil dispone que: «el que por acción u omisión causa daño a otro interviniendo culpa o negligencia, está obligado a reparar el daño causado». Conforme a reiterada jurisprudencia ${ }^{81}$ y doctrina ${ }^{82}$, los requisitos de la responsabilidad extracontractual, son: acción u omisión voluntaria culpable o cuanto menos negligente, producción de un daño o perjuicio, y relación de causalidad entre aquella actividad o inacción y el resultado.

Los citados elementos excepcionalmente concurrirán cuando la supuesta responsabilidad derive de una invitación a negociar. En efecto, la emisión de una invitación a negociar puede interpretarse como un acto capaz de generar responsabilidad extracontractual. Por tanto, el primero de los requisitos sí puede cumplirse. Dicha emisión, salvo casos de coacción, será voluntaria. Por consiguiente, el segundo aspecto también estaría presente. Sin embargo, es muy difícil que concurran los otros dos elementos.

Así, el inicio de los tratos preliminares no suele implicar más gastos que los derivados de las comunicaciones practicadas. Por ello, la manifestación de un simple deseo de negociar rara vez genera un desplazamiento de personas, porque la falta de determinación sobre la posible transacción impide saber si se puede alcanzar un punto de encuentro entre los intereses de las partes. En esa fase tan embrionaria las partes intentan evitar todos los gastos posibles, porque son conscientes que tendrán que asumirlos como coste perdido en el caso de que los tratos preliminares no finalicen con la conclusión del contra-

${ }^{80}$ Cfr. «Las Cartas de Intenciones» en Fusiones y Adquisiciones de Empresas, op. cit., pág. 90.

81 Cfr. STS de 21 de noviembre 2008.

82 Cfr. DÍEZ-PICAZO Y PONCE, L.-GULLÓN BALLESTEROS, A., Sistema de Derecho Civil, vol. II, $7^{\text {a }}$ ed., Madrid, Tecnos, 1995, pág. 598. 
to. Lo mismo podría decirse respecto a la posibilidad de perder oportunidades de negocio. Y es que el padre de familia del Código Civil ${ }^{83}$ no perdería un negocio seguro por una mera invitación a negociar. Por consiguiente, rara vez se genera un daño, y si éste se produce, dicho daño suele ser irrelevante cuantitativa y cualitativamente. En consecuencia, con carácter general una invitación a negociar no producirá daño indemnizable alguno ${ }^{84}$.

A su vez, una invitación a negociar difícilmente puede originar el nexo causal necesario entre el daño y el acto. Con independencia de la teoría causal que se siga ${ }^{85}$, una declaración de voluntad de iniciar unos tratos preliminares únicamente puede generar la legítima expectativa de que tales tratos preliminares comiencen. Según los principios generales del Derecho, las partes asumen el riesgo de que las negociaciones no concluyan con la celebración del contrato, excepto que haya habido una ruptura injustificada de las negociaciones ${ }^{86}$. Por consiguiente, la relación causal se limita a los daños provocados por la falta de inicio de las negociaciones. Como se ha explicado tales daños rara vez existirán. Además, siguiendo a DÍEZ-PICAZO Y PONCE podría concluirse que tales gastos deben asumirse en cualquier caso por la parte perjudicada porque «constituyen el riesgo implícito

${ }^{83}$ Cfr. art. 1.104 CC.

${ }^{84}$ Cfr. CAVESTANY, J., op. cit.

85 Siguiendo a DÍEZ-PICAZO Y PONCE y GULLÓN BALLESTEROS, puede decirse que las múltiples teorías formuladas respecto a la causalidad pueden diferenciarse en dos grupos. El primero de ellos está regido por el principio de que no puede hacerse ninguna diferenciación entre los diversos antecedentes que pueden confluir en el resultado dañoso. Todos tendrán el rango de causantes, siempre que se cumpla el siguiente postulado: un hecho es causa de otro cuando, si hubiera faltado el antecedente, no se hubiera producido el resultado (teoría de la equivalencia o de la condición sine qua non). Otro grupo está constituido por las teorías que destacan dentro del conjunto de antecedentes uno o varios de ellos para conceptuarlos como causa del resultado, evitando así la amplitud que tendría la responsabilidad con la teoría de la equivalencia. Sin embargo, las posiciones de los autores varían cuando se trata de establecer un criterio con arreglo al cual ha de procederse a aquella selección. Un sector sigue el de la adecuación (teoría de la causa adecuada), estimando como causa del daño el antecedente que es probable, posible o razonable que lo ocasione. Otra corriente doctrinal entiende que el hecho más próximo al daño deber ser su causa (teoría de la causa próxima). A su vez, se mantiene también que el hecho más eficiente es el decisivo (teoría de la causa eficiente), aunque las opiniones sobre la eficiencia son discrepantes. Pues, o bien se detecta en el hecho más activo (BIRKMEYER), o en el que tiene en sí mismo la fuerza determinante para producir el daño tal y como se ha dado (KOHLER). Cfr. op. cit., págs. 598 y ss.

${ }^{86} \mathrm{Al}$ respecto, ilustrativamente CARRASCO PERERA comenta que «creo que pueda decirse sin género de dudas que el destinatario de una invitación actúa por su propia cuenta y riesgo» (cfr. «Las Cartas de Intenciones» en Fusiones y Adquisiciones de Empresas, op. cit., pág. 101). 
de todo negocio» ${ }^{87}$. A su vez, tal falta de nexo causal impediría la aplicación de la doctrina del enriquecimiento sin causa ${ }^{88}$.

Por tanto, una invitación a negociar difícilmente puede originar responsabilidad extracontractual, porque no concurren los requisitos exigidos por el artículo 1.902 del Código Civil y la jurisprudencia y doctrina que lo interpretan.

En el caso de que una invitación a negociar sea aceptada, si podría entenderse que existe un contrato. En ese supuesto, hay un consentimiento bilateral sobre el inicio de las negociaciones de un contrato. Dicha invitación a negociar habitualmente concretará el tipo de contrato y se suministrará alguna información de su objeto, como la especie. Por consiguiente, hay una obligación suficientemente determinada como para constituir el objeto de un contrato. Aunque tal obligación no se trate de una "cosa», eso no impediría que la obligación de iniciar las negociaciones constituya el objeto del contrato, puesto que las obligaciones de hacer pueden ser objeto de contratos. Cuestión que no es controvertida en nuestro Derecho, ya que dicha posibilidad se contempla en la misma regulación del objeto de los contratos. En particular, el precepto 1.272 del Código Civil menciona los contratos de servicios imposibles como supuesto de inexistencia de objeto. Por tanto, los contratos de servicios posibles sí tienen objeto. Tal objeto no es otro que una obligación de hacer. En el caso de las invitaciones a negociar, la obligación de hacer consiste en iniciar las negociaciones.

La causa de una invitación a negociar aceptada es la promesa de la otra parte de iniciar las negociaciones. En efecto, el propio artículo 1.274 del Código Civil admite la posibilidad de que la promesa de servicio constituya la causa de un contrato. En consecuencia, la contraprestación de la promesa de la obligación de hacer de iniciar las negociaciones de una parte es la correspondiente promesa de la otra parte, según el citado precepto del Código Civil.

Por lo tanto, y aunque algún autor español considera lo contrario $^{89}$, parece lógico entender que una invitación a negociar aceptada sí, según el, puede generar eficacia contractual, puesto que hay un con-

87 Cfr. Fundamentos..., op. cit., pág. 324.

88 Cfr. CARRASCO PERERA, A., "Las Cartas de Intenciones» en Fusiones y Adquisiciones de Empresas, op. cit., pág. 101.

89 En este sentido parece pronunciarse CARRASCO PERERA al comentar: «respecto a las declaraciones no vinculantes, la «aceptación» mediante la suscripción no las convierte en contratos o compromisos contractuales. Bien porque a pesar de los términos de la aceptación, la delimitación objetiva del futuro acuerdo continúa siendo 
trato conforme al artículo 1.261 del Código Civil. La cuestión entonces estriba en determinar qué efectos contractuales produciría. Al respecto, siguiendo lo dispuesto en el precepto 1.258 del Código Civil, habría que concluir que una invitación a negociar únicamente podría vincular a lo establecido en ella y a todas las consecuencias que, según su naturaleza, sean conformes a la buena fe, al uso y a la ley. En consecuencia, una invitación a negociar aceptada únicamente debería obligar a iniciar los tratos preliminares y a negociar de buena fe.

El principal escollo entonces radica en determinar qué consecuencias tendría el incumplimiento. Respecto a la vulneración de la obligación de negociar de buena fe, parece que habría que atender a si se ha producido una ruptura injustificada de las negociaciones. Para ello siguiendo numerosa jurisprudencia ${ }^{90}$ deberían de concurrir los siguientes elementos: existencia de una razonable confianza respecto a la celebración del contrato, ausencia de justificación para la ruptura de las negociaciones, existencia de daño real para una de las partes y una relación de causalidad entre la ruptura de las negociaciones y el daño experimentado por una de las partes. Como se ha expuesto anteriormente, tales elementos difícilmente pueden concurrir.

No obstante, en el caso de que efectivamente estén presentes, siguiendo la mejor doctrina y jurisprudencia ${ }^{91}$ parece que únicamente habría que compensar el interés negativo. Es decir, el daño emergente. La aplicación del artículo 709 de la ley de Enjuiciamiento Civil parece excesivo e inadecuado para el incumplimiento de una obligación de iniciar las negociaciones.

Respecto al incumplimiento de la obligación de iniciar las negociaciones habría que indemnizar el daño que efectivamente se haya

muy indeterminada, bien porque aquellas declaraciones han quedado cubiertas por la cláusula (aceptada) de no vinculatoriedad» (cfr. «Las Cartas de Intenciones» en Fusiones y Adquisiciones de Empresas, op. cit., pág. 90). Las invitaciones a negociar propuestas en este estudio no establecen expresamente el carácter vinculante de la obligación de iniciar las negociaciones. Normalmente ni siquiera dicha obligación se contempla expresamente. Por tanto, según CARRASCO PERERA podrían considerarse unas declaraciones no vinculantes. Pero como se explicado, las invitaciones a negociar contendrían todos los elementos esenciales de un contrato y deberían tener eficacia contractual respecto a su contenido. Aunque las invitaciones a negociar serían no vinculantes respecto al contrato proyectado, que parece ser el ámbito de eficacia al que se refiere CARRASCO PERERA.

90 Cfr. SSTS de 26 de febrero 1994 y de 5 de abril 1999; SSAP de Madrid de 13 de septiembre 2000 y de León de 8 de febrero 2002.

91 Cfr. SAP de León de 8 de febrero 2002, SAP de Madrid de 24 de noviembre 2005; DÍEZ-PICAZO Y PONCE, L., Fundamentos..., $6^{\text {a }}$ ed., op. cit., pág. 325. 
producido. El cual rara vez se originará y más difícilmente se podrá demostrar su existencia y relación de causalidad con el incumplimiento. En cualquier caso, se debería tener en cuenta que habría que evitar una duplicidad de compensaciones por ambos incumplimientos para no generar un enriquecimiento injusto.

Por último, habría que decir que los efectos propuestos son acordes con los criterios económicos comentados por SCHWARTZ y SCOTT $^{92}$ sobre la posibilidad de indemnizar en casos de incumplimiento de acuerdos precontractuales. En efecto, si bien en este caso sí podría entenderse que las partes han acordado el tipo de proyecto, económicamente no sería aconsejable conceder una compensación, por cuanto las partes no habrían acordado la división operativa de facultades para realizar las inversiones que requiere el proyecto, ni las partes habrían acordado de forma básica el orden de las acciones que deben de realizar dentro del proyecto.

\section{CONCLUSIONES}

Las invitaciones a negociar se usan en diversos contextos, como en los casos en que una parte pide cotización a terceros, o incluso en contrataciones públicas, en las que las administraciones emiten unas solicitudes de información, pidiendo presupuestos aproximados y no vinculantes, para después iniciar la correspondiente licitación pública.

Dicha configuración precontractual implica que la invitación a negociar no es un contrato, puesto que no tiene el consentimiento de la otra parte, al ser un documento unilateral no aceptado. Por consiguiente, no puede generar eficacia contractual.

Conforme al artículo 1.902 del Código Civil y la jurisprudencia que lo interpreta, la responsabilidad extracontractual requiere una acción u omisión dolosa o negligente, que provoque un daño a un tercero. Tales elementos difícilmente pueden concurrir cuando una parte de forma unilateral expresa su deseo de iniciar unas negociaciones. Así, aunque se entienda que la declaración es la acción, que obviamente es voluntaria, y la parte receptora confíe de manera legítima en ella, rara vez se producirá un daño como consecuencia de dicha confianza. Por un lado, porque el inicio de los tratos preliminares no sue-

92 Cfr. «Precontractual Liability and Preliminary Agreements» en Harvard Law Review, $\mathrm{n}^{\circ} 120$, enero 2007, págs. 702 y ss. 
le implicar un coste mayor que el comenzar las comunicaciones. Por tanto, no se producen daños. Por otro lado, dichos daños difícilmente pueden ampararse en una legítima confianza en la declaración contenida en la invitación a negociar, puesto que es un principio general del Derecho que las partes asumen el riesgo de que las negociaciones no desemboquen en la conclusión de un contrato.

No obstante, la aceptación de una invitación a negociar podría permitir considerar que se ha concluido un contrato. Aunque nuevamente serían excepcionales los casos en que por el incumplimiento de la obligación de empezar a negociar o por el inicio de los tratos preliminares, pueda originarse, y por ende, deba indemnizarse daño alguno.

Por lo tanto, las invitaciones a negociar son manifestaciones de voluntad de iniciar las negociaciones. Dichas declaraciones carecen de ánimo de contratar. En consecuencia, las invitaciones a negociar no son vinculantes y difícilmente pueden generar responsabilidad alguna.

\section{BIBLIOGRAFÍA}

ALBALADEJO GARCÍA, M., Derecho Civil II Derecho de Obligaciones, $13^{\mathrm{a}}$ ed., Madrid, Edisofer, S.L., 2008.

ASÚA GONZÁLEZ, C. I., La culpa in contrahendo, Erandi, Servicio Editorial Universidad del País Vasco, $1^{\text {a }}$ ed., 1989.

BELTRÁN SÁNCHEZ, E., ORDUÑA MORENO, F. J. y otros, Curso de Derecho Privado, 13 ${ }^{\mathrm{a}}$ ed., Valencia, Tirant lo Blanch, 2010.

CABANILLAS SÁNCHEZ, A., "El ámbito de la responsabilidad precontractual o culpa in contrahendo» en Revista Crítica de Derecho Inmobiliario, no 628, Mayo-Junio 1995, págs. 764 y ss.

CARRASCO PERERA, A., «Las Cartas de Intenciones» en Fusiones y Adquisiciones de Empresas, Cizur Menor, Navarra, Thompson Aranzadi, 2004, págs. 87 a 143.

- «Cartas de intenciones, precontratos, responsabilidad in contrahendo y obligatoriedad de los tratos en la jurisprudencia española» en Aranzadi Civil, vol. III, 2005, págs. 2369 a 2392.

CAVANILLAS MÚGICA, S., «Sentencia de 14 de junio de 1999: responsabilidad por ruptura de tratos preliminares», en Cuadernos Civitas de Jurisprudencia Civil, nº 51, 1999, págs. 1231 a 1242 
CAVESTANY, J., "Letters of intent, precontratos y otros acuerdos preparatorios» en Expansión jurídico 7 de junio 2010, accesible en http://www.expansion.com/accesible/2010/06/07/juridicoopinion/1275925551.html.

Código Civil, Madrid, La Ley, septiembre 2012.

LOBATO DE BLAS, J., "Consideraciones sobre el concepto de tratos preliminares» en Revista General de Legislación y Jurisprudencia, $\mathrm{n}^{\circ} 6$ diciembre 1976, págs. 541 a 582.

DÍEZ-PICAZO Y PONCE, L., Fundamentos del Derecho Civil Patri-

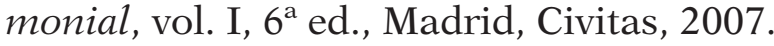

DÍEZ-PICAZO Y PONCE, L.-GULLÓN BALLESTEROS, A., Sistema de Derecho Civil, vol. II, $7^{\mathrm{a}}$ ed., Madrid, Tecnos, 1995.

FABRE-MAGNAN, M., Les obligations, Francia, Presses Universitaires de France, 2004.

GARCÍA RUBIO, M. P., La responsabilidad precontractual en el ordenamiento español, $1^{\text {a }}$ ed., Madrid, Tecnos, 1991.

HERNÁNDEZ GIL, A., Derecho de Obligaciones, T. 3, Madrid, Espasa Calpe, 1988.

LACRUZ BERDEJO, J. L. y otros, Nociones de Derecho Civil Patrimonial e introducción al Derecho, $4^{\mathrm{a}}$ ed., Madrid, Dykinson, 2004.

LASARTE ALVÁREZ, C., Principios de Derecho Civil III, $13^{\text {a }}$ ed., Madrid-Barcelona, Marcial Pons, 2010.

- Curso de Derecho Patrimonial, 16 a ed., Madrid, Tecnos, 2010.

LLODRÀ GRIMALT, F., «Letter of intent, carta de intenciones, precontrato», en Derecho de los negocios, n $^{\circ} 151$, abril 2003, págs. 1430 .

MARTÍN BERNAL, J. M., Nociones de Derecho Patrimonial, Madrid, Editorial Centro de Estudios Ramón Areces, S.A., 2003, pág. 358.

MEDINA ALCOZ, M., "La ruptura injustificada de los tratos preliminares: notas acerca de la naturaleza de la responsabilidad precontractual», en Revista Crítica de Derecho Inmobiliario ${ }^{\circ} 5$ 6/2005, Mayo-Junio 2005, págs. 78 a 106.

MENÉNDEZ MATO, J. C., La Oferta Contractual, Pamplona, Aranzadi, 1998.

MORENO QUESADA, B., La oferta de contrato. Génesis del contrato y 
responsabilidad antecontractual. Doctrina, legislación, comentarios, jurisprudencia, Barcelona, Colección Nereo, 1963.

PASCUAL ESTEVILL, L., Derecho de daños, T. II, $2^{\text {a }}$ ed., Barcelona, Bosch, 1995, págs. 1023 y ss.

PUIG BRUTAU, J., Compendio de Derecho Civil, vol. II, Barcelona, Bosch, 1997, págs. 215 a 226 y 313 a 328.

SCHWARTZ, A.-SCOTT, R. E., "Precontractual Liability and Preliminary Agreements» en Harvard Law Review, n 120 , enero 2007, págs. 661 a 707.

SIMÓ SEVILLA, D. y otros, Instituciones de Derecho Privado, T. III, vol. $2^{\circ}$, Madrid, Civitas, 2005, pág. 335 a 352.

TERSILLA, S. «La lettera di intenti nella trattativa per 1 acquisizione di un pacchetto azionario di riferimento" en Diritto del Comercio Internazionale, v. 17, 2003, págs. 507 a 525.

\section{VI. ÍNDICE DE SENTENCIAS CITADAS}

\section{Tribunal Supremo (Sala Civil)}

1. STS de 22 de mayo 1970 (RJ 1970, 2289).

2. STS de 10 de octubre 1980 (RJ 1980, 3623).

3. STS de 7 de junio 1986 (RJ 1986, 3296).

4. STS de 11 de marzo 1988 (RJ 1988, 1958).

5. STS de 13 de diciembre 1989 (RJ 1989, 8824).

6. STS de 4 de julio 1991 (RJ 1991, 5325).

7. STS de 26 de marzo 1993 (RJ 1993, 2395).

8. STS de 26 de febrero 1994 (RJ 1994, 1198).

9. $\quad$ STS de 19 de julio 1994 (RJ 1994, 6698).

10. STS de 14 de octubre 1996 (RJ 1996, 7107).

11. STS de 3 de junio 1998 (RJ 1998, 3715).

12. STS de 5 de abril 1999 (RJ 1999, 1873).

13. STS de 11 de abril 2000 (RJ 2000, 2434).

14. STS de 20 de abril 2001 (RJ 2001, 5282). 
15. STS de 30 de junio 2005 (RJ 2005, 5089).

16. STS de 13 de octubre 2005 (RJ 2005, 7235).

17. STS de 21 de noviembre 2008 (RJ 2009, 144).

18. STS de 30 de marzo 2010 (RJ 2010, 2538).

19. STS de 3 de noviembre 2010 (RJ 2010, 8019).

20. STS de 22 de diciembre 2010 (RJ 2011, 1559).

21. STS de 12 de julio 2011 (JUR 2011, 263253).

22. STS de 30 de septiembre 2011 (JUR 2011, 350425).

\section{Tribunal Supremo (Sala Social)}

23. STS de 16 de septiembre 2004 (RJ 2004, 7304).

\section{Audiencias Provinciales}

24. SAP de Zaragoza de 30 de mayo 1992 (AC 1992, 789).

25. SAP de Madrid de 13 de septiembre 2000 (JUR 2000, 279377).

26. SAP de Vizcaya de 13 de octubre 2000 (AC 2000, 2441).

27. SAP de la Audiencia Provincial de León de 8 de febrero 2002 (JUR 2002, 11375).

28. SAP de Barcelona de 10 de diciembre 2002 (JUR 2003, 192155).

29. SAP de Madrid de 24 de noviembre 2005 (JUR 2006, 66115).

30. SAP de Barcelona de 28 de febrero 2006 (JUR 2006, 110924).

31. SAP de Albacete de 21 de junio 2008 (JUR 2008, 354967). 
